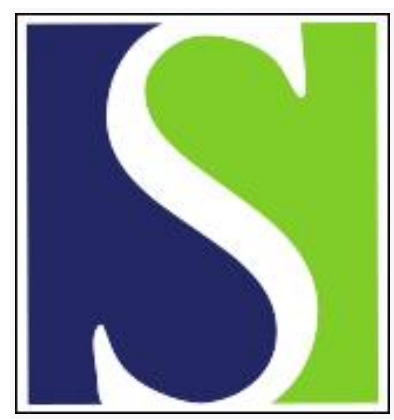

Scand J Work Environ Health 2015;41(5):460-466

https://doi.org/10.5271/sjweh.3508

Published online: 17 Jun 2015, Issue date: 01 Sep 2015

Predictors of permanent work disability among $\leq 50$-year-old patients undergoing percutaneous coronary intervention

by Gunn J, Kiviniemi T, Biancari F, Kajander O, Mäkikallio T, Eskola M, Ilveskoski E, Korpilahti K, Wistbacka J-O, Anttila V, Heikkinen J, Airaksinen J

Long-term working capacity in young coronary artery disease patients under 50 years of age has not been previously published. This is a socioeconomically important population with potentially decades of working life ahead.

Affiliation: Heart Center, Turku University Hospital, PO Box 52, 20521 Turku, Finland. jarmo.gunn@tyks.fi

Key terms: age; coronary artery disease; percutaneous coronary intervention; permanent work disability; predictor; work disability; young age

This article in PubMed: www.ncbi.nlm.nih.gov/pubmed/26079321 


\title{
Predictors of permanent work disability among $\leq 50$-year-old patients undergoing percutaneous coronary intervention
}

\author{
by Jarmo Gunn, MD, PhD, ${ }^{1}$ Tuomas Kiviniemi, MD, PhD, ${ }^{1}$ Fausto Biancari, MD, PhD, ${ }^{2}$ Olli Kajander, MD, \\ PhD, ${ }^{3}$ Timo Mäkikallio, MD, PhD, ${ }^{2}$ Markku Eskola, MD, PhD, ${ }^{3}$ Erkki Ilveskoski, MD, PhD, ${ }^{3}$ Kari Korpilahti, \\ MD, PhD, ${ }^{4}$ Jan-Ola Wistbacka, MD, PhD, ${ }^{4}$ Vesa Anttila, MD, PhD, ${ }^{2}$ Jouni Heikkinen, MD, PhD, ${ }^{2}$ Juhani \\ Airaksinen, Professor ${ }^{1}$
}

Gunn J, Kiviniemi T, Biancari F, Kajander 0, Mäkikallio T, Eskola M, Ilveskoski E, Korpilahti K, Wistbacka J-0, Anttila $\mathrm{V}$, Heikkinen J, Airaksinen J. Predictors of permanent work disability among $\leq 50$-year-old patients undergoing percutaneous coronary intervention. Scand J Work Environ Health. 2015;41(5):460-466. doi:10.5271/sjweh.3508

Objectives This study aimed to describe the incidence and periprocedural predictors of permanent work disability (PWD) pension among patients $\leq 50$ years old who underwent percutaneous coronary intervention (PCI).

Methods Patient records of 910 consecutive patients undergoing PCI at four Finnish hospitals in 2002-2012 were reviewed for baseline and procedural data and late adverse events. Data on permanent work disability (PWD) pension allocation were acquired from the Finnish Centre for Pensions, which governs the statutory pension security in Finland.

Results Mean follow-up was 41 [standard deviation (SD) 31] months. Altogether 103/910 (11.3\%) of patients were on PWD by the end of follow-up, 60 (58.3\%) for cardiac diagnoses (cumulative freedom from PWD 81\% at 7 years). Independent predictors of PWD were post procedural stroke [hazard ratio (HR) 4.7, 95\% confidence interval (95\% CI) 1.8-11.9], post procedural myocardial infarction (MI) (HR 3.3, 95\% CI 1.8-6.0), diabetes (HR 2.0, 95\% CI 1.1-3.7), discharge diuretics (HR 3.5, 95\% CI 2.1-5.9), and increasing age (HR 1.2, 95\% CI 1.1-1.3). Predictors of PWD for cardiac diagnoses were post procedural stroke and MI, discharge diuretics, and use of calcium-channel blockers, diabetes and older age.

Conclusions Patients $\leq 50$ years old undergoing PCI are at a high risk for subsequent permanent disability for cardiac diagnoses. This finding underscores the need for reinforcing adherence to secondary prevention by cardiac rehabilitation and early collaboration with occupational health care professionals.

Key terms age; coronary artery disease; young.

Hard end points such as mortality, morbidity, and target vessel revascularization rates are well documented after percutaneous coronary intervention (PCI), but relatively scarce data exist on occupational health outcomes. Among patients of working age, permanent disability pension has major socioeconomic consequences for both the individual and the society. Nevertheless, little is known about the rate and reasons for permanent work disability (PWD).

In this pre-specified analysis of the CRAGS (Coronary aRtery diseAse in younG adultS) registry we sought to assess the role of periprocedural factors related to PCI in the incidence, indications, and determinants of permanent disability pension in long-term follow-up of $\leq 50$-year-old patients who have undergone PCI $(1-3)$.

\section{Methods}

This study is part of a larger multicenter collaboration designed to describe outcomes among $\leq 50$-yearold patients revascularized for coronary artery disease (CRAGS). This substudy comprised all 1003 consecu-

1 Heart Center, Turku University Hospital and University of Turku, Turku, Finland.

2 Oulu University Hospital, Oulu, Finland.

3 Heart Hospital, Tampere University Hospital and University of Tampere, School of Medicine, Tampere, Finland.

4 Vaasa Central Hospital, Vaasa, Finland.

Correspondence to: Jarmo Gunn, Heart Center, Turku University Hospital, PO Box 52, 20521 Turku, Finland. [E-mail: jarmo.gunn@tyks.fi] 
tive PCI $\leq 50$-year-old patients who underwent PCI at three university hospitals (Oulu, Tampere and Turku) and one central hospital (Vaasa) in Finland during 20022012. Invasive treatment of coronary disease is mainly centralized and the participating hospitals are the treating hospitals within their geographical catchment area.

The study complies with the Declaration of Helsinki, and the locally appointed ethics committees of participating hospital have approved the research protocol.

Data on PWD pension (starting date, primary and secondary diagnosis) were acquired from the Finnish Centre for Pensions, which governs the statutory pension security in Finland, and which in turn consists of a defined benefit earnings-related pension that accrues from work as well as residence-based national pension and guarantee pension that ensure minimum security. The statutory pension system in Finland consists of two main parts - earnings-related and residence-based national pensions. The earnings-related pension, managed by various providers who belong to the Finnish Centre for Pensions, covers the entire workforce, including the self-employed. None of the patients were eligible for old-age pension during follow-up. Ninetythree patients on PWD already prior to index procedure were excluded from further analysis. Periprocedural data and baseline comorbidities along with data on post procedural morbidity were acquired from local hospital registries which enabled complete follow up as treatment of the events of interest (cardiac- and cerebrovascular) are centralized. Data on date and mode of death was acquired from the Finnish national registry, Statistics Finland.

Data on the number of insured and the incidence and category (cardiovascular, musculoskeletal and psychiatric) of PWD in each age group in the general population between 2007-2011 was obtained from the Finnish Center for Pensions. Statistics from a group comprised of 45-year-old insured patients were used for comparison with the study population (mean age 45 years). Major adverse cardiac and cerebrovascular event (MACCE) is defined as a composite of myocardial infarction (MI), repeat revascularization and stroke. Death was not included as MACCE was evaluated as a factor influencing PWD.

The main outcomes of interest were PWD defined as grant of disability pension during follow-up and predictors thereof. Secondary measures were predictors of cardiac disability defined as PWD with a cardiac diagnosis. Statistical analysis was performed with SPSS Statistics version 22.0 (IBM, Armonk, NY, USA) and R version 2.15.3. Categorical variables are reported as counts and percentages, continuous variables as mean and standard deviation (SD) or median and interquartile range (IQR). Fisher's exact test, Chi square, independent samples T-test and Kaplan-Meier were used for univariate analy- sis. Cox proportional hazards models were employed to identify predictors of permanent disability by including clinically important variables with a P-value $<0.10$ on univariable analysis into the multivariable models.

\section{Results}

By the end of a median follow-up of 41 (SD 31) months, there were 103 cases of PWD $(11.3 \%$ of the study population).

Time to grant of disability pension was 34 (SD 29) months overall and 29 (SD 27) for cardiac PWD versus 42 (SD 32) for other types of PWD ( $\mathrm{P}<0.001)$.

Primary diagnoses for PWD were cardiac in $43 / 103$ (41.7\%), psychiatric in 15/103 (14.6\%), and musculoskeletal in 16/103 (15.5\%) patients. Diagnoses for PWD in the general population were cardiac in $5.7 \%$, psychiatric in $40.1 \%$, and musculoskeletal in $24.4 \%$. In the study population, $11 / 15$ primary psychiatric diagnoses were depression and 19/103 (18.4\%) of patients had depression as a primary or secondary diagnosis for PWD.

For the 93 patients who were excluded from analysis for preprocedural PWD, primary diagnoses for PWD were: cardiac for $12(12.9 \%)$, musculoskeletal for 18 (19.4\%), and psychiatric for 26 (28\%) patients.

Baseline variables and outcomes for patients with and without post procedural PWD are detailed in table 1. Patients who developed PWD were slightly older and had a higher baseline comorbidity burden compared to patients without later disability.

A total of 24/73 (32.9\%) patients with a recurrent MI, $36 / 149(24.2 \%)$ patients with a repeat revascularization procedure, and 6/12 (50\%) patients who experienced a post procedural stroke were on PWD by end of followup. Kaplan-Meier estimates of freedom from PWD for patients with and without post procedural MACCE are represented in figure 1. Kaplan-Meier estimates for overall freedom from PWD were $88.0 \%$ at 4 years and $81 \%$ at 7 years. Actuarial freedom from PWD at 4 years in the general population aged 45 years old was $97.2 \%$.

Independent predictors of PWD on Cox regression are detailed in table 2. PCI on left anterior descending branch was an independent protective factor against PWD [hazard ratio (HR) $0.6,95 \%$ confidence interval (95\% CI) 0.4-0.9, $\mathrm{P}=0.019]$.

Patients with PWD for cardiac diagnosis were older [47 (SD 3) versus 45 (SD 5) years, $\mathrm{P}=0.001$ ], more often had dyslipidemia ( $38.3 \%$ versus $25.7 \%, \mathrm{P}=0.03$ ), hypertension ( $48.3 \%$ versus $28.8 \%, \mathrm{P}=0.001)$, and diabetes ( $26.7 \%$ versus $11.3 \%, \mathrm{P}<0.001)$. Kaplan-Meier freedom from cardiac PWD was $89.6 \%$ at 7 years. Independent predictors of cardiac PWD were age, diabetes, discharge diuretics, discharge calcium-channel blockers, 
Table 1. Baseline and postprocedural characteristics of patients $<50$ years old with or without permanent disability compensation after percutaneous coronary intervention. $[A P=$ angina pectoris; $A S A=$ acetosalicylic acid; $A T 2=$ angioten $\sin 2 ; C A B G=$ coronary artery bypass grafting; $C A D=$ coronary artery disease eGFR=estimated glomerular filtration rate (MDRD formula); $L A D=l e f t$ anterior descending artery; LCX=left circumflex artery; LVEF=left ventricular ejection fraction; $\mathrm{MI}=$ myocardial infarction; MSK=musculoskeletal; NSTEMI=non ST-elevation $\mathrm{MI}$; $\mathrm{PCl}=$ percutaneous coronary intervention, RCA=right coronary artery; STEMI=ST-elevation MI].

\begin{tabular}{|c|c|c|c|c|c|}
\hline Group & $\begin{array}{c}\text { No } \\
\text { disability } \\
(\mathrm{N}=807)\end{array}$ & $\%$ & $\begin{array}{c}\text { Permanent } \\
\text { disability } \\
(\mathrm{N}=103)\end{array}$ & $\%$ & P-value \\
\hline Age (years) & 45 & & 47 & & $<0.001$ \\
\hline Females & 121 & 15.0 & 22 & 21.4 & 0.095 \\
\hline eGFR $<60 \mathrm{ml} / \mathrm{min} / 1.72 \mathrm{~m}^{2}$ & 11 & 1.4 & 11 & 5.8 & 0.002 \\
\hline Family history of CAD & 426 & 53.1 & 58 & 56.3 & 0.53 \\
\hline Treatment for dyslipidemia & 198 & 24.6 & 43 & 41.7 & $<0.001$ \\
\hline Treatment for hypertension & 228 & 28.3 & 46 & 44.7 & 0.001 \\
\hline Smoker & 570 & 70.6 & 76 & 73.8 & 0.51 \\
\hline Treatment for diabetes & 85 & 10.6 & 27 & 26.2 & $<0.001$ \\
\hline History of MI & 42 & 5.2 & 14 & 13.6 & $<0.001$ \\
\hline History of PCl & 26 & 3.2 & 14 & 13.6 & $<0.001$ \\
\hline History of CABG & 2 & 0.2 & 1 & 1.0 & 0.23 \\
\hline Extracardiac arteriopathy & 8 & 1.0 & 2 & 2.0 & 0.22 \\
\hline Congestive heart failure & 3 & 0.4 & 1 & 1.0 & 0.39 \\
\hline Cerebrovascular disease & 7 & 0.9 & 3 & 2.9 & 0.059 \\
\hline Indication for revascularization & & & & & 0.034 \\
\hline STEMI & 330 & 40.9 & 37 & 36.6 & \\
\hline NSTEMI & 248 & 30.8 & 25 & 24.8 & \\
\hline Unstable angina & 72 & 8.9 & 8 & 7.9 & \\
\hline Stable AP & 156 & 19.4 & 31 & 30.7 & \\
\hline \multicolumn{6}{|l|}{ Procedural characteristics } \\
\hline Urgency & & & & & 0.01 \\
\hline Elective & 160 & 20.0 & 33 & 32.4 & \\
\hline Urgent & 442 & 55.2 & 52 & 51.0 & \\
\hline Emergent & 199 & 24.8 & 17 & 16.7 & \\
\hline LVEF & & & & & 0.36 \\
\hline$>50 \%$ & 442 & 75.7 & 52 & 68.4 & \\
\hline $30-50 \%$ & 133 & 22.8 & 22 & 28.9 & \\
\hline$<30 \%$ & 9 & 1.5 & 2 & 2.6 & \\
\hline Left main PCI & 7 & 0.9 & 0 & & 0.60 \\
\hline Stage & 42 & 5.4 & 3 & 3.0 & 0.32 \\
\hline $\mathrm{PCl}$ on & 467 & 57.9 & 48 & 46.6 & 0.03 \\
\hline $\mathrm{PCl}$ or & 167 & 20.7 & 22 & 21.4 & 0.88 \\
\hline $\mathrm{PCl}$ or & 285 & 35.3 & 45 & 43.7 & 0.096 \\
\hline Drug & 327 & 57.8 & 66 & 64.1 & 0.27 \\
\hline Incomplete revascularization & 143 & 17.7 & 28 & 27.2 & 0.022 \\
\hline \multicolumn{6}{|l|}{ Discharge medication } \\
\hline ASA & 799 & 99.5 & 101 & 98.1 & 0.089 \\
\hline Clopidogrel & 756 & 94.1 & 103 & 100 & 0.012 \\
\hline Warfarin & 29 & 3.6 & 6 & 5.8 & 0.53 \\
\hline Statin & 782 & 97.3 & 99 & 96.1 & 0.51 \\
\hline T2-antagonist & 473 & 59.4 & 62 & 60.8 & 0.79 \\
\hline Betabl & 738 & 92.3 & 96 & 94.1 & 0.50 \\
\hline Diuretic & 43 & 5.4 & 21 & 20.8 & $<0.001$ \\
\hline Ca-blocker & 48 & 6.1 & 15 & 14.9 & 0.001 \\
\hline \multicolumn{6}{|l|}{ Outcomes } \\
\hline In-hospital stroke & 0 & 0 & & & \\
\hline Late stroke & 6 & 0.7 & 6 & 5.8 & $<0.001$ \\
\hline Repeat revascularization & 113 & 14.0 & 36 & 35.0 & $<0.001$ \\
\hline Myocardial infarction & 49 & 6.1 & 24 & 23.3 & $<0.001$ \\
\hline Death & 15 & 1.9 & 6 & 5.8 & 0.012 \\
\hline Cardiac diagnosis for disability & & & 60 & 58.3 & \\
\hline $\begin{array}{l}\text { Psychiatric diagnosis for } \\
\text { disability }\end{array}$ & & & 28 & 27.2 & \\
\hline MSK diagnosis for disability & & & 22 & 21.4 & \\
\hline Primary diagnosis cardiac & & & 43 & 41.7 & \\
\hline Primary diagnosis psychiatric & & & 15 & 14.6 & \\
\hline Primary diagnosis MSK & & & 16 & 15.5 & \\
\hline
\end{tabular}

post procedural stroke, and post procedural myocardial infarction (table 3.). PCI on left anterior descending artery (LAD) emerged as an independent protective factor against cardiac PWD (HR 0.4, 95\%CI 0.2-0.7, $\mathrm{P}=0.002)$.

\section{Discussion}

The present study provides details on a socioeconomically important subpopulation of $\leq 50$-year-old patients referred for PCI. This is a patient group with a potential for longevity and, as an age group, in the prime of their input in the workplace. Previous studies have reported that $64-87 \%$ of young patients return to work within 3-15 months after PCI (4-7); many of the studies, however, are from the 80s and 90s making comparison with contemporary PCI techniques and modern employment policies very difficult. Furthermore, the studies do not describe long-term working capacity after PCI. Comparisons are rendered difficult also by the fact that the present registry does not contain data on employment status, but rather whether or not the patient has been deemed capable of work. The excellent results survival-wise $(1,8)$ in the present registry are offset by a high cumulative incidence at 7 years follow-up of PWD (19.0\%), and $58.3 \%$ of patients with PWD had a cardiac diagnoses as the primary indication for disability pension. The patients with cardiac PWD left the work force one year earlier than those with non-cardiac indication for pension. The 4-year freedom for patients (median age 45 years) was $88.0 \%$ compared with $97.3 \%$ in the general population aged 45 years based on statistics from the Finnish Centre for Pensions.

Important predictor baseline values of both overall and specifically cardiac disability were increasing age, diabetes, and previous coronary interventions which are known predictors of MACCE among young patients undergoing PCI $(8,9)$.

The predictive role of diabetes is not surprising, since diabetics in general have a worse prognosis after revascularization than non-diabetics, and diabetes by itself also negatively influences working ability (10-13). Post procedural adverse events were associated with permanent disability both in univariate and multivariate analysis. A possible place for improvement might be a more complete approach to revascularization; patients with permanent disability pension more often had incomplete revascularization, which according to the literature is a risk factor for adverse outcomes and it is possible that a more aggressive approach towards a complete revascularization in these young patients might reduce the need for disability pension $(14,15)$.

On the other hand, most of the post-PCI revascular- 


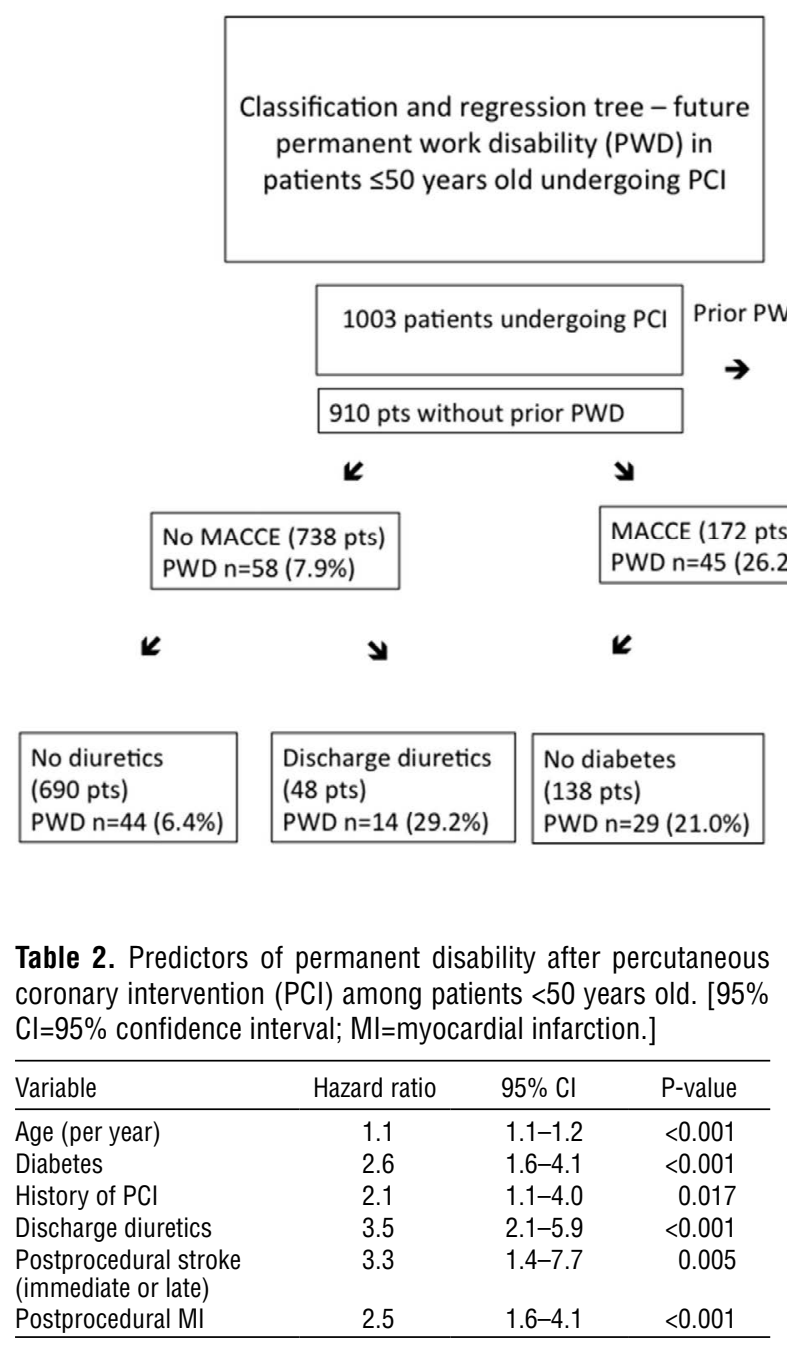

ization procedures in this registry were performed due to disease progression suggesting that shortcomings in secondary prevention play a larger role (3). Based on the results, $<50$-year-old patients have an almost universal optimal medication at the time of hospital discharge from PCI. However, in general, $25-60 \%$ of patients discontinue optimal discharge medication one year after PCI (16-18). Moreover, young age in itself is a known predictor of both adverse events as well as poor adherence to secondary prevention $(19,20)$. Patients in this study also had a noteworthy incidence $(27.2 \%$ of patients on PWD) of psychiatric morbidity leading or contributing to PWD; psychiatric symptomatology, even if not directly leading to disability, causes poor adherence to medication $(18,21)$, which in turn can affect outcomes and cardiac health entailing impaired working health. It has also been shown that improvement in depressive symptoms leads to better adherence to secondary prevention among cardiac patients $(22,23)$. Serious mental illness itself is also a well described risk
Figure 1. CART (Classification and regression tree analysis) for discriminators of permanent work disability following percutaneous coronary intervention $(\mathrm{PCl})$ among patients $\leq 50$ years old.

\section{Diabetes \\ (34 pts) \\ PWD $n=16(47.1 \%)$}

Table 3. Predictors of permanent cardiac disability after percutaneous coronary intervention (PCI) in patients $<50$ years old. [95\% $\mathrm{Cl}=95 \%$ confidence interval; $\mathrm{Ml}=$ myocardial infarction.]

\begin{tabular}{lccr}
\hline Variable & Hazard ratio & $95 \% \mathrm{Cl}$ & P-value \\
\hline Age (per year) & 1.2 & $1.1-1.3$ & 0.001 \\
Diabetes & 2.0 & $1.1-3.7$ & 0.032 \\
Discharge diuretics & 4.9 & $2.5-9.4$ & $<0.001$ \\
Discharge Ca-blockers & 2.9 & $1.3-6.2$ & 0.009 \\
Postprocedural stroke (im- & 4.7 & $1.8-11.9$ & 0.001 \\
mediate or late) & & & \\
Postprocedural MI & 3.3 & $1.8-6.0$ & $<0.001$ \\
\hline
\end{tabular}

factor for cardiovascular morbidity and mortality but even less dramatic psychiatric morbidity such as depression incurs an elevated risk of cardiovascular events (24-26). Even though the percentage of actual psychiatric diagnoses in the present study was in fact lower than in the PWD cases of the general population a psychosocial burden is likely in young patients undergoing PCI. Alluding to this for example is the high prevalence of smoking of about $70 \%$ which is distinctly higher than in the general Finnish population (Finnish National Institute for Health and Healthcare 2013 Tobacco Statistics) and the high prevalence of smoking is typical for lower socioeconomic demographics $(3,27)$.

Cardiac rehabilitation, in addition to improving functional status cost-effectively $(28,29)$, has a protective effect against cardiac events further preserving function and working ability $(30,31)$. Improving participation in cardiac rehabilitation programs can be difficult, but attendance can be improved by addressing system- and patient-level barriers (32) while physical barriers other 


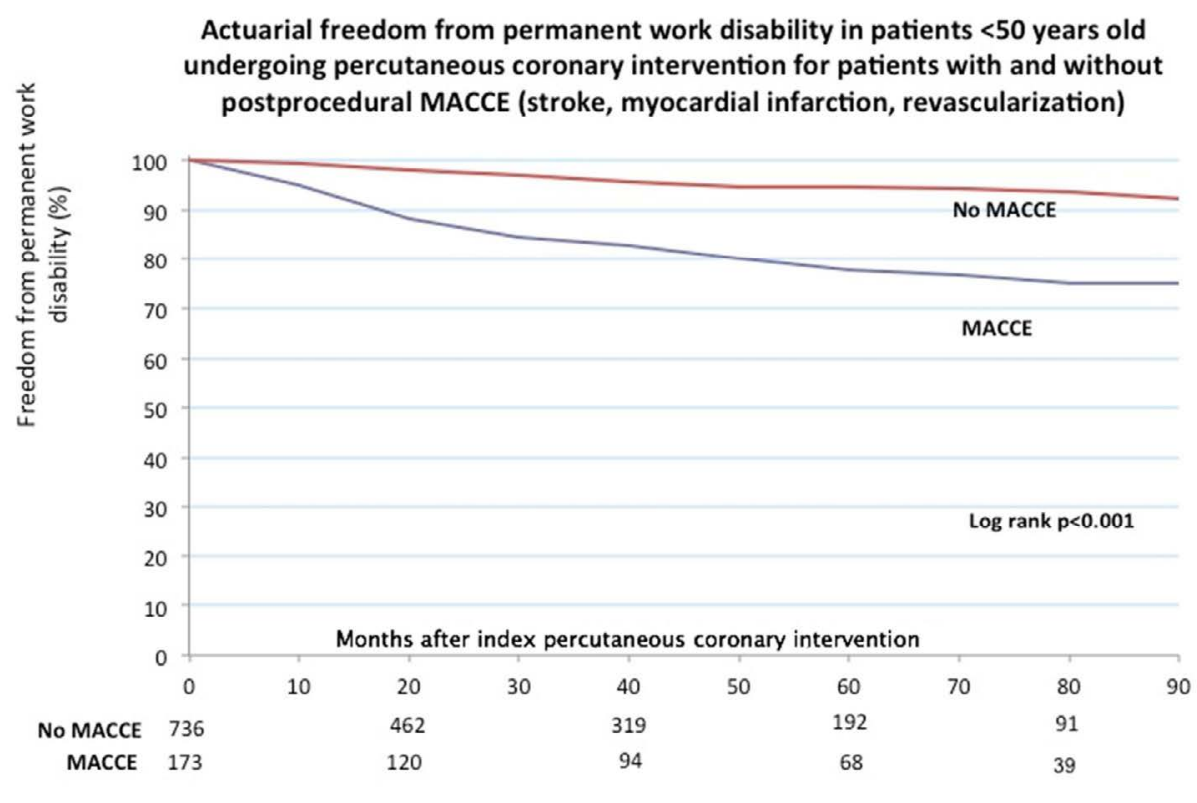

Figure 2. Freedom from permanent work disability among patients $\leq 50$ years old undergoing percutaneous coronary intervention (PCI). [MACCE=major adverse cerebrovascular and cardiac event (stroke, revascularization, acute myocardial infarction).] than coronary disease, such as those prevalent in the current study population, can still prevent attendance (33). It is also noteworthy that the deleterious effects of incomplete revascularization can also be mitigated by rehabilitation, and cardiac rehabilitation improves adherence to secondary prevention (34). Early and active collaboration with occupational healthcare physicians and rehabilitation could be potential targets for improving later working capacity in young patients.

Gender did not independently influence the risk of disability unlike the earlier literature on disability in general and after PCI (35-37). Remarkably even the higher baseline disease burden among women in the present study (data not shown) did not alter the incidence of PWD.

In a previous extensive study from Sweden - a country with a healthcare and pension system very similar to Finland - PWD rates were higher compared to our study (36). Authors reported almost a two-fold incidence (29.3\%) of disability pension compared with this study during a 5-year follow-up. The patients in the Swedish study, however, were older with over $80 \%$ being $\geq 50$ years at index procedure. Although Zetterström et al's study focused on psychosocial factors of PWD (36), which are also inextricably present in this study, it also highlighted the impact of disease burden at baseline on later occupational status. While psychosocial factors play a large role in future PWD, socioeconomic factors alone typically do not elicit rehabilitative and occupational healthcare measures. The combination, at least, of socioeconomic disadvantage, psychiatric symptomatology and cardiovascular disease should act as a red flag entailing supportive measures to uphold working capacity.

\section{Limitations}

These findings need to be interpreted with caution. The main limitation of this study is its base in one healthcare and health insurance system; although this makes direct numerical applicability into other systems unreliable it does give a good overview of the comorbidities and predictors of disability in young PCI patients. This study also does not assess employment status, only permanent disability. The actual percentage of patients out of the workforce can thus be even higher. Also missing are other sociodemographic data such as occupational and educational background which were not recorded in the registry as the main focus of the present study was on periprocedural factors and their association with disability. The retrospective nature of the study is also a limitation, but a prospective study on this issue would hardly be feasible because of the limited number of young patients treated yearly in each center. In addition, the present registry has all the inherent limitations of an observational study, including individual risk-based decision-making in treatment choices. Compliance data on secondary preventive medication was not available.

\section{Concluding remarks}

Patients $<50$ years old undergoing PCI are at high risk of subsequent PWD pension. Post procedural adverse events such as MI, repeat revascularization, and cerebrovascular events are the major predictors of later disability. A more active approach to secondary prevention, cardiac rehabilitation and occupational health is needed among young patients after PCI. 


\section{Funding}

The Finnish Foundation for Cardiovascular Research, Helsinki, Finland (TOK, KEJA), supported this study.

\section{Conflict of interest}

KEJA discloses advising Bayer and Boston Scientific and lecture fees from Cardiome and Boehringer Ingelheim.

\section{References}

1. Biancari F, Gudbjartsson T, Heikkinen J, Anttila V, Mäkikallio T, Jeppsson A et al. Comparison of 30-day and 5-year outcomes of percutaneous coronary intervention versus coronary artery bypass grafting in patients aged $\leq 50$ years (the Coronary aRtery diseAse in younG adultS Study). Am J Cardiol. 2014;114(2):198-205. http://dx.doi.org/10.1016/j. amjcard.2014.04.025.

2. Biancari F, Onorati F, Faggian G, Heikkinen J, Anttila V, Jeppsson A et al. Determinants of outcome after isolated coronary artery bypass grafting in patients aged $\leq 50$ years (from the Coronary aRtery diseAse in younG adults study). Am J Cardiol. 2014;113(2):275-8. http://dx.doi. org/10.1016/j.amjcard.2013.08.038.

3. Lautamäki A, Airaksinen KE, Kiviniemi T, Vinco G, Ribichini F, Gunn J et al. Prognosis and disease progression in patients under 50 years old undergoing PCI: the CRAGS (Coronary aRtery diseAse in younG adultS) study. Atherosclerosis. 2014;235(2):483-7. http://dx.doi. org/10.1016/j.atherosclerosis.2014.05.953.

4. Fitzgerald ST, Becker DM, Celentano DD, Swank R, Brinker J. Return to work after percutaneous transluminal coronary angioplasty. Am J Cardiol. 1989;64(18):1108-12. http:// dx.doi.org/10.1016/0002-9149(89)90861-8.

5. Danchin N, Juilliere Y, Selton-Suty C, Vaillant G, Pernot C, Gilgenkrantz JM et al. Return to work after percutaneous transluminal coronary angioplasty: a continuing problem. Eur Heart J. 1989;10 Suppl G:54-7.

6. Laird-Meeter K, Erdman RA, van Domburg R, Azar AJ, de Feyter PJ, Bos E et al. Probability of a return to work after either coronary balloon dilatation or coronary bypass surgery. Eur Heart J. 1989;10(10):917-22.

7. Bergvik S, Sørlie T, Wynn R. Coronary patients who returned to work had stronger internal locus of control beliefs than those who did not return to work. Br J Health Psychol. 2012;17(3):596-608. http://dx.doi.org/10.1111/j.20448287.2011.02058.x.

8. Lichtman JH, Wang Y, Jones SB, Leifheit-Limson EC, Shaw LJ, Vaccarino $\mathrm{V}$ et al. Age and sex differences in inhospital complication rates and mortality after percutaneous coronary intervention procedures: evidence from the $\operatorname{NCDR}\left({ }^{\circledR}\right)$. Am Heart J. 2014;167(3):376-83. http://dx.doi.org/10.1016/j. ahj.2013.11.001.

9. Ergelen M, Uyarel H, Gorgulu S, Norgaz T, Ayhan E, Akkaya $\mathrm{E}$ et al. Comparison of outcomes in young versus nonyoung patients with ST elevation myocardial infarction treated by primary angioplasty. Coron Artery Dis. 2010;21(2):72-7. http://dx.doi.org/10.1097/MCA.0b013e328334a0f6.

10. Banning AP, Westaby S, Morice MC, Kappetein AP, Mohr FW, Berti S et al. Diabetic and nondiabetic patients with left main and/or 3-vessel coronary artery disease: comparison of outcomes with cardiac surgery and paclitaxel-eluting stents. J Am Coll Cardiol. 2010;55(11):1067-75. http://dx.doi. org/10.1016/j.jacc.2009.09.057.

11. Hasdai D, Granger CB, Srivatsa SS, Criger DA, Ellis SG, Califf RM et al. Diabetes mellitus and outcome after primary coronary angioplasty for acute myocardial infarction: lessons from the GUSTO-IIb Angioplasty Substudy. Global Use of Strategies to Open Occluded Arteries in Acute Coronary Syndromes. J Am Coll Cardiol. 2000;35(6):1502-12. Erratum in: J Am Coll Cardiol. 2000;36(2):following 659. http:// dx.doi.org/10.1016/S0735-1097(00)00591-X.

12. Gilbert J, Raboud J, Zinman B: Meta-analysis of the effect of diabetes on restenosis rates among patients receiving coronary angioplasty stenting. Diabetes Care. 2004;27:990-4. http:// dx.doi.org/10.2337/diacare.27.4.990.

13. Herquelot E, Guéguen A, Bonenfant S, Dray-Spira R. Impact of diabetes on work cessation: data from the GAZEL cohort study. Diabetes Care. 2011;34(6):1344-9. http://dx.doi. org/10.2337/dc10-2225.

14. Garcia S, Sandoval Y, Roukoz H, Adabag S, Canoniero $\mathrm{M}$, Yannopoulos D et al. Outcomes after complete versus incomplete revascularization of patients with multivessel coronary artery disease: a meta-analysis of 89,883 patients enrolled in randomized clinical trials and observational studies. J Am Coll Cardiol. 2013;62(16):1421-31. http://dx.doi. org/10.1016/j.jacc.2013.05.033.

15. Gao Z, Xu B, Yang YJ, Yuan JQ, Chen J, Chen JL et al. Longterm outcomes of complete versus incomplete revascularization after drug-eluting stent implantation in patients with multivessel coronary disease. Catheter Cardiovasc Interv. 2013;82(3):343-9. http://dx.doi.org/10.1002/ccd.24799.

16. Latry P, Martin-Latry K, Lafitte M, Peter C, Couffinhal T. Dual antiplatelet therapy after myocardial infarction and percutaneous coronary intervention: analysis of patient adherence using a French health insurance reimbursement database. EuroIntervention. 2012;7(12):1413-9. http://dx.doi. org/10.4244/EIJV7I12A221.

17. Cole JA, Brennan AL, Ajani AE, Yan BP, Duffy SJ, Loane P et al. Cardiovascular medication use following percutaneous coronary intervention: the Australian experience. Cardiovasc Ther. 2014;32(2):47-51. http://dx.doi.org/10.1111/17555922.12060

18. Son YJ, Kim SH, Park JH. Role of depressive symptoms and self-efficacy of medication adherence in Korean patients after successful percutaneous coronary intervention. Int $\mathrm{J}$ Nurs Pract. 2014;20(6):564-72. http://dx.doi.org/10.1111/ ijn. 12203 . 
19. Griffo R, Ambrosetti M, Tramarin R, Fattirolli F, Temporelli PL et al; ICAROS investigators. Effective secondary prevention through cardiac rehabilitation after coronary revascularization and predictors of poor adherence to lifestyle modification and medication. Results of the ICAROS Survey. Int J Cardiol. 2013;167(4):1390-5. http://dx.doi.org/10.1016/j. ijcard.2012.04.069.

20. Zhu B, Zhao Z, McCollam P, Anderson J, Bae JP, Fu H et al. Factors associated with clopidogrel use, adherence, and persistence in patients with acute coronary syndromes undergoing percutaneous coronary intervention. Curr Med Res Opin. 2011;27(3):633-41. http://dx.doi.org/10.1185/0300799 5.2010 .551657 .

21. Dempe C, Jünger J, Hoppe S, Katzenberger ML, Möltner A, Ladwig $\mathrm{KH}$ et al. Association of anxious and depressive symptoms with medication nonadherence in patients with stable coronary artery disease. J Psychosom Res. 2013;74(2):122-7. http://dx.doi.org/10.1016/j.jpsychores.2012.12.003.

22. Bauer LK, Caro MA, Beach SR, Mastromauro CA, Lenihan E, Januzzi JL et al. Effects of depression and anxiety improvement on adherence to medication and health behaviors in recently hospitalized cardiac patients. Am J Cardiol. 2012;109(9):1266-71. http://dx.doi.org/10.1016/j. amjcard.2011.12.017.

23. Reibis R, Jannowitz C, Halle M, Pittrow D, Gitt A, Völler H. Management and outcomes of patients with reduced ejection fraction after acute myocardial infarction in cardiac rehabilitation centers. Curr Med Res Opin. 2015;31(2):211-9. http://dx.doi.org/10.1185/03007995.2014.977854.

24. Tiihonen J, Lönnqvist J, Wahlbeck K, Klaukka T, Niskanen L, Tanskanen A, et al. 11-Year follow-up of mortality in patients with schizophrenia: a population-based cohort study (FIN11 study). Lancet. 2009;374(9690):620-7. http://dx.doi. org/10.1016/S0140-6736(09)60742-X.

25. Osborn DPJ, Levy G, Nazareth I, Petersen I, Islam A, King MB. Relative risk of cardiovascular and cancer mortality in people with severe mental illness from the United Kingdom's General Practice Research Database. Arch Gen Psychiatry. 2007;64(2):242-9. http://dx.doi.org/10.1001/ archpsyc.64.2.242.

26. Seldenrijk A, Vogelzangs N, Batelaan NM, Wieman I, van Schaik DJ, Penninx BJ. Depression, anxiety and 6-year risk of cardiovascular disease. J Psychosom Res. 2015;78(2):123-9. http://dx.doi.org/10.1016/j.jpsychores.2014.10.007.

27. Filion KB, Steffen IM, Duval S, Jacobs DR Jr, Blackburn H, Luepker RV. Trends in smoking among adults from 1980 tp 2009: the Minnesota heart survey. Am J Public Health. 2012;102(4):705-13. http://dx.doi.org/10.2105/ AJPH.2011.300162.
28. Yu CM, Lau CP, Chau J, McGhee S, Kong SL, Cheung BM et al. A short course of cardiac rehabilitation program is highly cost effective in improving long-term quality of life in patients with recent myocardial infarction or percutaneous coronary intervention. Arch Phys Med Rehabil. 2004;85(12):1915-22. http://dx.doi.org/10.1016/j.apmr.2004.05.010.

29. Wong WP, Feng J, Pwee KH, Lim J. A systematic review of economic evaluations of cardiac rehabilitation. BMC Health Serv Res. 2012;12:243. http://dx.doi.org/10.1186/14726963-12-243.

30. Dendale P, Hansen D, Berger J, Lamotte M. Long-term cost-benefit ratio of cardiac rehabilitation after percutaneous coronary intervention. Acta Cardiol. 2008;63(4):451-6. http:// dx.doi.org/10.2143/AC.63.4.2033043.

31. Dendale P, Berger J, Hansen D, Vaes J, Benit E, Weymans M. Cardiac rehabilitation reduces the rate of major adverse cardiac events after percutaneous coronary intervention. Eur J Cardiovasc Nurs. 2005;4(2):113-6. http://dx.doi. org/10.1016/j.ejcnurse.2004.11.003.

32. Neubeck L, Freedman SB, Clark AM, Briffa T, Bauman A, Redfern J. Participating in cardiac rehabilitation: a systematic review and meta-synthesis of qualitative data. Eur J Prev Cardiol. 2012;19(3):494-503. http://dx.doi. org/10.1177/1741826711409326.

33. De Vos C, Li X, Van Vlaenderen I, Saka O, Dendale P, Eyssen $\mathrm{M}$ et al. Participating or not in a cardiac rehabilitation programme: factors influencing a patient's decision. Eur J Prev Cardiol. 2013;20(2):341-8. http://dx.doi. org/10.1177/2047487312437057.

34. Rechciński T, Kałowski M, Kasprzak JD, Trzos E, Kurpesa M. Beneficial effects of cardiac rehabilitation in patients with incomplete revascularization after primary coronary angioplasty. Eur J Phys Rehabil Med. 2013;49(6):785-91.

35. Claussen B, Dalgard OS. Disability pensioning: the gender divide can be explained by occupation, income, mental distress and health. Scand J Public Health. 2009;37(6):590-7. http:// dx.doi.org/10.1177/1403494809105795.

36. Zetterström K, Vaez M, Alexanderson K, Ivert T, Pehrsson $\mathrm{K}$, Hammar $\mathrm{N}$ et al. Disability pension after coronary revascularization: a prospective nationwide register-based Swedish cohort study. Eur J Prev Cardiol. 2015;22(3):304-11. http://dx.doi.org/10.1177/2047487313518472.

37. Voss M, Ivert T, Pehrsson K, Hammar N, Alexanderson $\mathrm{K}$, Nilsson $\mathrm{T}$ et al. Sickness absence following coronary revascularisation. A national study of women and men of working age in Sweden 1994-2006. PLoS One. 2012;7(7):e40952. http://dx.doi.org/10.1371/journal. pone. 0040952 .

Received for publication: 10 March 2015 